\title{
MINIMALLY INVASIVE MITRAL VALVE REPLACEMENT: PORT-ACCESS TECHNIQUE, FEASIBILITY, AND MYOCARDIAL FUNCTIONAL PRESERVATION
}

Daniel S. Schwartz, MD

Greg H. Ribakove, MD

Eugene A. Grossi, MD

Patricia M. Buttenheim, MA

Jess D. Schwartz, MD

Robert M. Applebaum, MD

Itzhak Kronzon, $\mathrm{MD}^{\mathrm{a}}$

F. Gregory Baumann, PhD

Stephen B. Colvin, MD

Aubrey C. Galloway, MD
Objective: This experiment examined the feasibility of minimally invasive port-access mitral valve replacement via a $2.5 \mathrm{~cm}$ incision. Methods: The study evaluated valvular performance and myocardial functional recovery in six mongrel dogs after port-access mitral valve replacement with a St. Jude Medical prosthesis (St. Jude Medical, Inc., St. Paul, Minn.). Femoro-femoral cardiopulmonary bypass and a balloon catheter system for myocardial protection with cardioplegic arrest (Heartport, Inc., Redwood City, Calif.) were used. The mitral valve was replaced through a $2.5 \mathrm{~cm}$ port in the left side of the chest, and the animals were weaned from bypass. Cardiac function was measured before and at 30 and 60 minutes after bypass. Left ventricular pressure and electrical conductance volume were used to calculate changes in load-independent indexes of ventricular function. Results: Each procedure was successfully completed. Recovery of left ventricular function was excellent at 30 and 60 minutes after bypass compared with the prebypass values for elastance (30 minutes $=4.04 \pm 0.97$ and 60 minutes $=4.27 \pm 0.57$ vs prebypass $=4.45 \pm$ $0.96 ; p=0.51)$ and for preload recruitable stroke work ( 30 minutes $=76.23 \pm$ 4.80 and 60 minutes $=71.21 \pm 2.99$ vs prebypass $=71.23 \pm 3.75 ; p=0.45$ ). Preload recruitable work area remained at $96 \%$ and $85 \%$ of baseline at 30 and 60 minutes $(p=$ not significant). In addition, transesophageal echocardiography demonstrated normal prosthetic valve function, as well as normal regional and global ventricular wall motion. Autopsy revealed secure annular-sewing apposition and normal leaflet motion. Conclusions: These results suggest that minimally invasive mitral valve replacement using percutaneous cardiopulmonary bypass with cardioplegic arrest is technically reproducible, achieves normal valve placement, and results in complete cardiac functional recovery. Minimally invasive mitral valve replacement is now feasible, and clinical trials are indicated. (J Thorac Cardiovasc Surg 1997;113:1022-31)
A a result of recent advances in technology and instrumentation, the concepts of minimally invasive or less invasive surgery can be applied to a

From the Division of Cardiothoracic Surgery, Department of Surgery, and the Division of Cardiology, ${ }^{2}$ Department of Medicine, New York University Medical Center, New York, N.Y.

Submitted as a Paul C. Samson Resident Prize Manuscript.

Supported in part by grants from Heartport, Inc., and St. Jude Medical, Inc.

Read at the Twenty-second Annual Meeting of The Western Thoracic Surgical Association, Maui, Hawaii, June 26-29, 1996

Received for publication July 3, 1996; revisions requested July 30 , 1996; revisions received Dec. 27, 1996; accepted for publication Dec. 27, 1996.

Address for reprints: Greg H. Ribakove, MD, New York University Medical Center, 530 First Ave., Suite 6D, New York, NY 10016.

Copyright (C) 1997 by Mosby-Year Book, Inc.

$0022-5223 / 97 \$ 5.00+0 \quad \mathbf{1 2 / 6 / 8 0 1 0 1}$ variety of complex heart operations. The anticipated benefit to patients is the ability to provide all of the advantages of open cardiac surgical operations with decreased pain, morbidity, and recovery time. In a previous article, ${ }^{1}$ we evaluated a system of cardiopulmonary bypass (CPB) and myocardial protection with cardioplegic arrest using a catheter system (EndoCPB, Heartport, Inc., Redwood City, Calif.). In that study the catheter and cardioplegia delivery system were found to be as safe and effective as standard open chest CPB with cardioplegic arrest. In the present study we applied this CPB balloon catheter system to a canine animal model and used port-access technology (Heartport) to perform mitral valve replacement with a St. Jude Medical valve prosthesis (St. Jude Medical, Inc., St. Paul, Minn.). This was done both under direct vision and with the aid of video-thoracoscopy through a $2.5 \mathrm{~cm}$ left lateral thoracotomy using several conventional valve suturing techniques. 
The purposes of this study were (1) to describe a port-access technique of minimally invasive mitral valve replacement and (2) to determine whether this technique of mitral valve replacement is technically reproducible and achieves normal valve placement and function, with preservation of myocardial function after the operation.

\section{Materials and methods}

Study group. Six heartworm-free mongrel dogs (25 to $30 \mathrm{~kg}$ ) were supported with femoro-femoral CPB and had mitral valve replacement with a St. Jude Medical prosthesis via a $25 \mathrm{~mm}$ left lateral thoracotomy port. Each animal served as its own control in that baseline hemodynamic and load-independent measurements of cardiac performance were compared with the same measurements taken after the procedure. All animals were given humane care in compliance with the "Principles of Laboratory Animal Care" formulated by the National Society for Medical Research and the "Guide for the Care and Use of Laboratory Animals" prepared by the Institute of Laboratory Animal Resources and published by the National Institutes of Health (NIH Publication No. 86-23, revised 1985).

Surgical preparation. All animals were initially anesthetized with a $4 \%$ solution of thiamylal $(0.5 \mathrm{mg} / \mathrm{kg})$. They were maintained on a regimen of metocurine iodide $(0.5$ $\mathrm{mg} / \mathrm{kg}$ ) and a mixture of isoflurane and oxygen after endotracheal intubation and placement on a mechanical ventilator. All animals were monitored throughout the entire procedure with electrocardiography and measurement of carotid arterial pressure (Koenigsberg Instruments, Inc., Pasadena, Calif.), pulmonary artery and central venous pressures with a pulmonary artery catheter (Arrow, Reading, Pa.), oxygen saturation by means of an external pulse oximeter, and carbon dioxide by means of a capnometer. Arterial blood gases and $\mathrm{pH}$ were kept in the normal range by adjusting inspired oxygen concentration and minute ventilation or by administering sodium bicarbonate. Electrolyte and hematocrit levels were also monitored at appropriate intervals throughout the procedure. No blood transfusions were given.

Technique of eatheter placement. The technique of catheter placement for minimally invasive CPB has been described. ${ }^{1}$ In brief, all catheters were placed with the chest closed after systemic heparinization (100 U/kg) (Fig. 1). A femoral venous catheter (17F cannula, model 58517 , DLP, Inc., Grand Rapids, Mich.) was placed through a left femoral venous cutdown and fluoroscopically guided (MCA 30 Ratheon, Tokyo, Japan) over a guide wire to a position just within the superior vena cava. The left femoral artery was cannulated with a femoral arterial catheter (14F, model 57414, DLP). Both catheters were then connected to the bypass pump (Shiley S-100A Bubble Oxygenator, Shiley, Inc., Irvine, Calif., and Pemco roller pump, model 5745, Pemco, Inc., Cleveland, Ohio) in a standard fashion. Venous return was aided by attachment of the return venous cannula to a centrifugal pump (Bio-pump, Medtronic Bio-Medicus, Eden Prairie, Minn.). Next, an endovascular pulmonary artery venting catheter (Endopulmonary Vent, Heartport) was inserted into the external jugular vein and guided into position over a flow-directed pulmonary artery balloon catheter by means of fluoroscopy. An endovascular aortic clamp (Endoaortic Clamp, Heartport) was positioned under fluoroscopic guidance via the contralateral femoral artery into the ascending aorta over a guide wire. Positioning of the balloon at the end of the endovascular aortic clamp in the aortic root was confirmed with instillation of a small aliquot of dilute radiopaque contrast medium (Hypaque sodium, Sanofi Winthrop Pharmaceuticals, New York, N.Y.) through the central lumen which communicates with the tip of the catheter positioned in the aortic root. The balloon was positioned so that it rested in the aorta without occlusion of the coronary ostia or aortic arch vessels. Antegrade cardioplegic solution was delivered through the central lumen of this catheter, which also acted as an aortic root vent. Aortic root pressure was monitored continuously through a third separate lumen. In the present study an additional catheter was inserted into the opposite external jugular vein and positioned into the coronary sinus over a guide wire with the aid of fluoroscopy (Fig. 2). This percutaneous coronary sinus catheter (Endosinus Catheter, Heartport) was used to infuse retrograde cardioplegic solution and monitor coronary sinus pressure.

CPB and delivery of cardioplegic solution. All animals were supported by total femoro-femoral CPB, cooled to a temperature of $20^{\circ} \mathrm{C}$, and maintained on CPB at a flow rate of $50 \mathrm{ml} / \mathrm{kg}$ per minute. Arterial oxygen tension was kept above $70 \mathrm{~mm} \mathrm{Hg}$, and the mean arterial pressure on CPB was maintained at $60 \mathrm{~mm} \mathrm{Hg}$ by adjusting bypass flow. The ascending aorta was occluded by inflation of the balloon at the end of the endovascular aortic clamp, and balloon pressure was monitored. Each animal received Freme's cardioplegic solution with oxygenated blood (ratio 4:1) cooled to $6^{\circ} \mathrm{C}$ in a $\mathrm{BCD}$ Plus Heat Exchanger (Shiley). Initially through the distal end of the endovascular aortic clamp an antegrade dose of $20 \mathrm{ml} / \mathrm{kg}$ highpotassium cardioplegic solution (20 to $24 \mathrm{mEq} / \mathrm{L}$ final concentration) was delivered to arrest the heart. Subsequent doses of $10 \mathrm{ml} / \mathrm{kg}$ low-potassium mixture ( 8 to 12 $\mathrm{mEq} / \mathrm{L}$ final concentration) cardioplegic solution were given through the retrograde coronary sinus catheter, or via the antegrade route in the two animals in which coronary sinus catheterization was not possible, at 15minute intervals. All doses were given at a rate of at least $75 \mathrm{ml} / \mathrm{min}$ and the infusion pressures were monitored. The hematocrit value during CPB remained above $25 \%$ in all cases. The pulmonary artery and the aortic root were vented throughout bypass and drained into the oxygenator reservoir. Aortic root pressure and pulmonary artery pressures were also monitored. At the conclusion of the procedure, the blood temperature was warmed to above $35^{\circ} \mathrm{C}$ and the aorta was unclamped. If necessary, the heart was defibrillated with external paddles. The heart was then allowed to rewarm to $37^{\circ} \mathrm{C}$. Data acquisition was continued for 60 minutes after the completion of CPB.

Technique of port-access mitral valve replacement. The mitral valve was replaced in this minimally invasive model with the use of specially designed instruments and an oval thoracic port (Heartport). Visualization was aided 


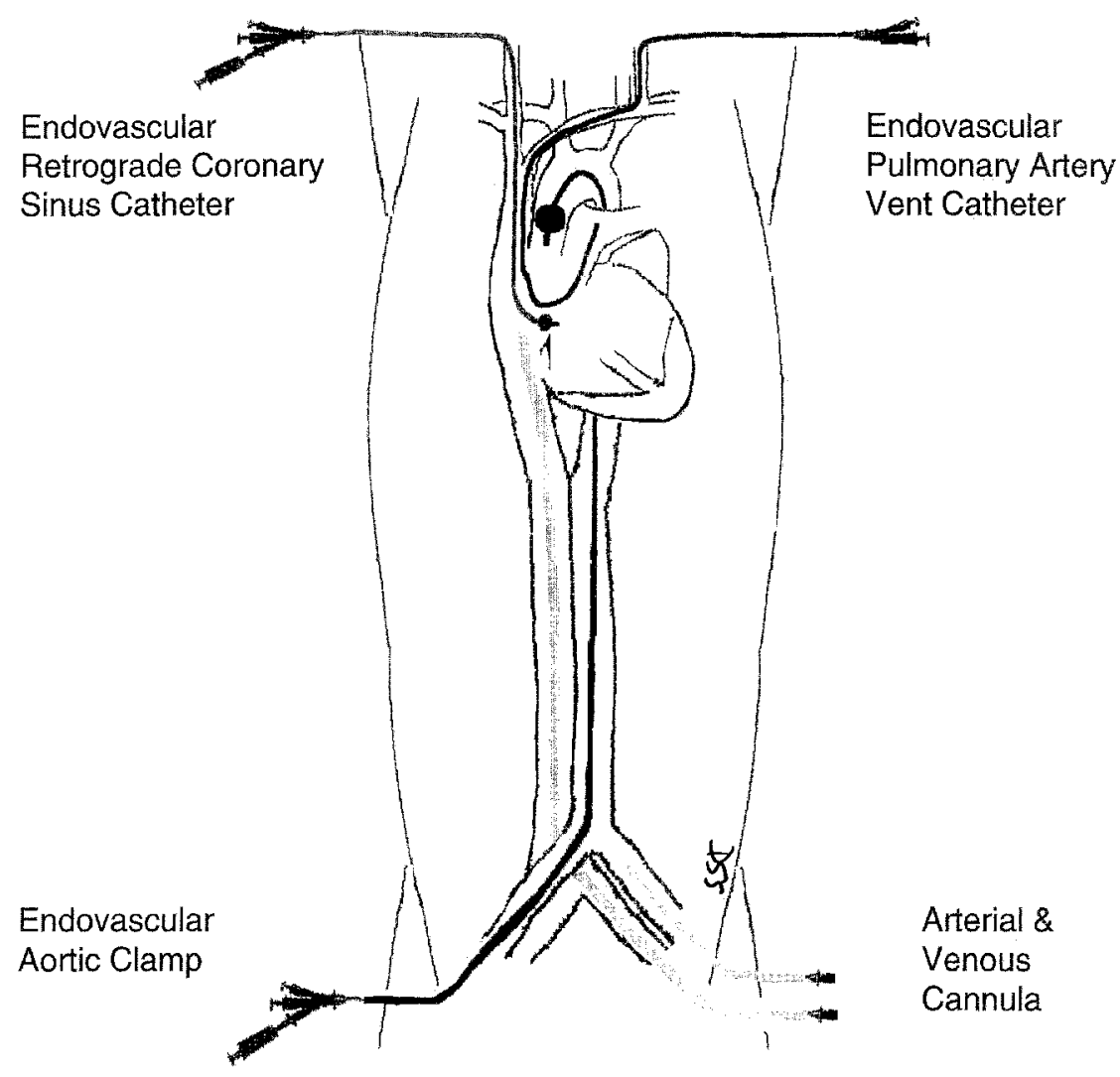

Fig. 1. Schematic diagram outlining the percutaneous femoro-femoral bypass and endovascular ballooncatheter system used in this series of experiments. The venous and arterial cannulas are connected to the bypass pump. The endovascular aortic clamp is inserted through the femoral artery. The pulmonary artery vent is inserted though the left jugular vein and the percutaneous venting catheter is inserted through the right jugular vein.

by video-assisted thoracoscopy. The animals were placed with the right side down at 15 degrees. A $2.5 \mathrm{~cm}$ incision was made in the left third or fourth intercostal space and the oval thoracic port was inserted (Fig. 3). An additional $10 \mathrm{~mm}$ port was placed in the adjacent proximal intercostal space through which the thoracoscope was inserted. The animal was supported by CPB as previously described and the heart was arrested. A pericardiectomy was performed over the left atrial appendage and the left atrial appendage was grasped with a DeBakey grasper, triangulated, and suspended from the chest wall with suture material brought out through the chest wall and secured with hemostats. The left atrium was opened with a longitudinal incision. The mitral valve was inspected, and the anterior leaflet was excised.

The mitral valve anulus was measured with a valve sizer, and the appropriate St. Jude Medical valve was sutured in place in a counterclockwise fashion by means of an atrial to ventricular technique. The sutures were placed through the prosthesis outside the chest cavity, and then the valve was lowered into proper position with the aid of a specially designed valve handle (Heartport), which could articulate and then be passed through the oval thoracic port. The sutures were tied either directly or, at times, with the aid of a specially designed knot pusher (Heartport). The valve seating and leaflet motion were then inspected and tested.

Air was removed from the heart as follows: (1) the animal was placed into the Trendelenburg position, (2) the ventricle was filled with blood by increasing gradient from the pump, (3) the atrium was partially closed with a continuous suture, (4) the heart was then gently massaged to extrude air, (5) the lungs were gently ventilated, (6) the aortic root and pulmonary artery vents were placed on suction and the heart was filled with blood as the endovascular crossclamp was deflated, and (7) the atrium was fully closed and the suture tied. After deairing was complete, the heart was defibrillated as necessary.

Measurement of left ventricular volume and pressure. Instantaneous left ventricular volumes were measured by means of the conductance method as previously described..$^{2-4}$ In brief, ventricular volume and pressure were measured with an integrated conductance volume and pressure micromanometer catheter for continuous on-line ventricular volume and pressure (Combicath, Sentron, Rhoden, The Netherlands). Calibration for absolute volume was corrected by measuring parallel conductance before each set of data was acquired. ${ }^{5}$ 
The conductance catheter was placed through the aortic valve and aligned along the long axis of the left ventricle, and the position was confirmed by fluoroscopy. A separate balloon catheter was placed into the inferior vena cava via a separate femoral vein puncture. When inflated, it was able to produce transient changes in preload. With left ventricular volume and pressure being recorded during changes in preload, a series of pressure-volume loops were generated and stored on a PC computer with the aid of a software package (Conduct-PC; Cardiodynamics bv, Leiden, The Netherlands) and the Sigma DF5 cardiac function analyzer (Cardiodynamics).

Myocardial contractile data acquisition and analysis. Load-independent and parallel conductance measurements were made before CPB (baseline), 30 minutes after the completion of $\mathrm{CPB}$, and 60 minutes after the completion of CPB. Three sets of data were acquired during each measurement period. Each set of data acquisition lasted 30 seconds and was recorded over a range of left ventricular end-diastolic volumes produced by the transient (15 second) caval occlusion. The method for measuring cardiac function was based on algorithms developed by other investigators. ${ }^{6-9}$ The indexes of regional left ventricular systolic contractile function calculated were the preload recruitable stroke work (PRSW), the preload recruitable work area (PRWA), and maximal regional elastance.

Pressure measurements. Aortic root and pulmonary artery pressure were recorded at 15-minute intervals during CPB. Antegrade and retrograde cardioplegia injection pressures were also measured and recorded.

Echocardiographic assessment of valve and heart function. After each mitral valve replacement and after weaning from CPB, two-dimensional transesophageal echocardiography (Hewlett-Packard Sonos 1000 with $5 \mathrm{MHZ}$ biplane transesophageal probe, Hewlett-Packard Company, Palo Alto, Calif.) with a color flow study was performed to assess prosthetic valve motion and valve seating and to identify any abnormal areas of flow acceleration. Also, ventricular and septal wall motion were assessed.

Statistical methods. Data were analyzed by the SPSS for Windows statistical software program (SPSS, Inc., Chicago, Ill.). All results are expressed as the mean \pm standard deviation. The statistical significance of changes in load-independent indexes of ventricular function were compared by repeated-measures analysis of variance. Significance was determined at the $5 \%$ level.

\section{Results}

CPB, delivery of cardioplegic solution, and ventricular decompression. Six mongrel dogs were successfully supported by femoro-femoral CPB with the use of a balloon catheter system for aortic crossclamping and protected cardioplegic arrest. Hemodynamic data are listed in Table I. All animals had mitral valve replacement with a St. Jude Medical prosthesis performed through a $2.5 \mathrm{~cm}$ thoracic port with left atrial exposure. All hearts arrested within 90 seconds after institution of antegrade cardiople-

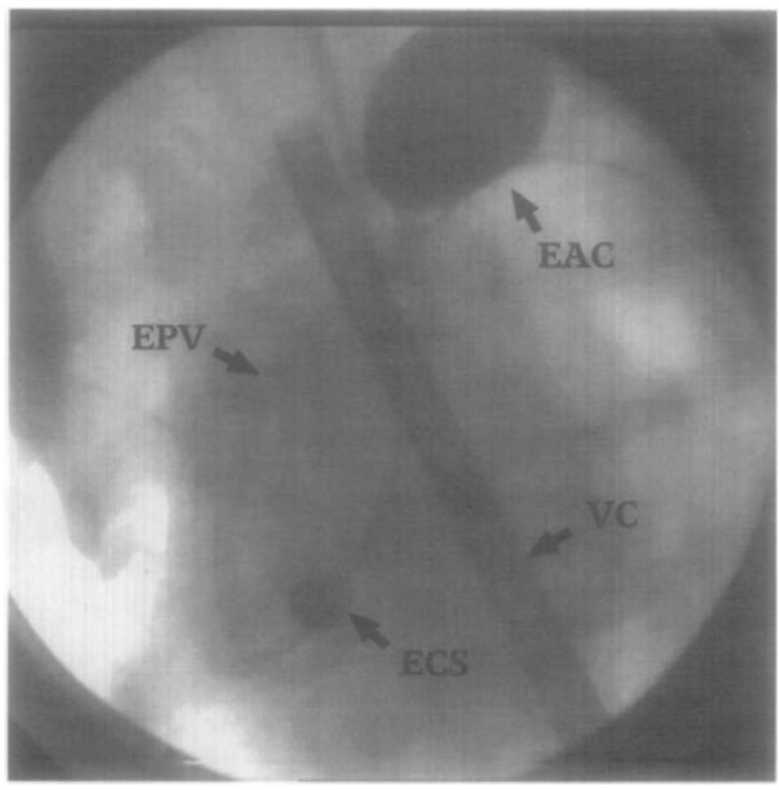

Fig. 2. Roentgenogram illustrating proper position of the endovascular aortic clamp $(E A C)$ in the ascending aorta with opacification of the balloon at the tip of the catheter. The endovascular coronary sinus catheter $(E C S)$ is properly positioned with the balloon inflated and opacified. Contrast material can be infused into the coronary sinus to confirm proper position. The endovascular pulmonary artery venting catheter $(E P V)$ and the long venous cannula $(V C)$ are overlying the cardiac silhouette.

gia. This was followed by retrograde cardioplegia $(n=4)$ or antegrade cardioplegia $(n=2)$ throughout the remainder of the procedure.

In cases in which coronary sinus catheter injection of cardioplegic solution was used, the pressure averaged $32.5 \pm 3.1 \mathrm{~mm} \mathrm{Hg}$. On the other hand, antegrade cardioplegia injection pressures were slightly higher $(39.7 \pm 5.1 \mathrm{~mm} \mathrm{Hg})$. In all cases adequate decompression of the heart was possible, with the average pulmonary artery and aortic root pressures remaining low throughout the period of cardioplegic arrest and cardiac venting $(1.3 \pm 1.8$ $\mathrm{mm} \mathrm{Hg}$ and $0 \pm 0.7 \mathrm{~mm} \mathrm{Hg}$, respectively).

Global myocardial contractile function. When the instantaneous intracavitary left ventricular pressure was plotted against the ventricular volume, pressure-volume loops resulted. At baseline before the institution of CPB and at 30 minutes and 60 minutes after the completion of $\mathrm{CPB}$, myocardial function was measured, and the results are presented in Figs. 4 to 6. The mean linear correlation coefficient for all these measurements was 99\%. There were no significant changes with 


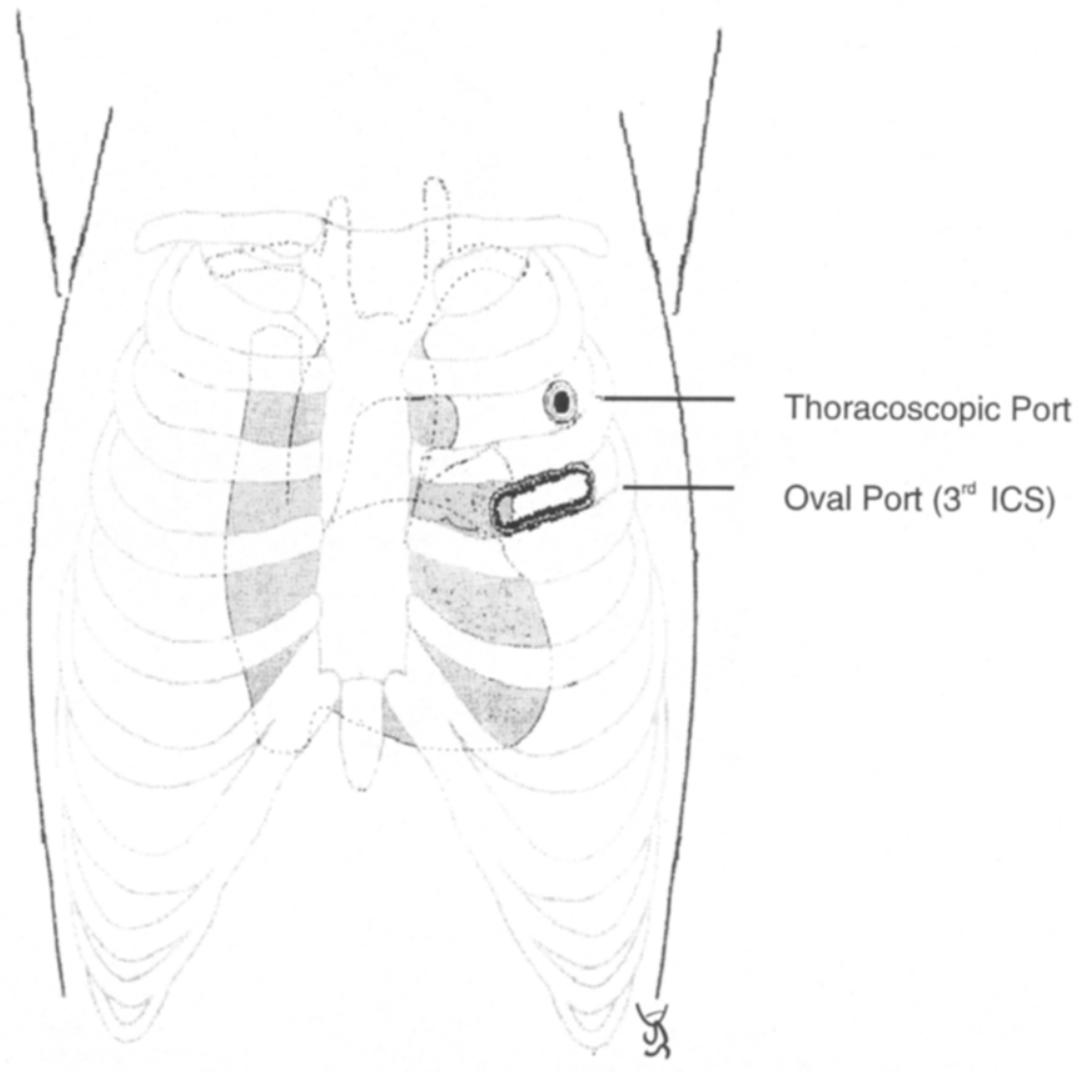

Fig. 3. The mitral valve is replaced through the left atrial appendage under direct vision and with the aid of thoracoscopy through a $25 \mathrm{~mm}$ oval thoracic port placed in the third or fourth intercostal space (ICS). The thoracoscope is introduced through a separate $10 \mathrm{~mm}$ port placed in either the intercostal space above or below the oval port.

Table I. Minimally invasive $M V R$ operative data

$\begin{array}{lc}\text { CPB duration (min) } & 88.3 \pm 13.2 \\ \text { Crossclamp time (min) } & 55.6 \pm 10.3 \\ \text { Heart rate baseline (beats/min) } & 108.3 \pm 12.1 \\ \text { Heart rate after MVR (beats/min) } & 109.3 \pm 14.1 \\ \text { Aortic root vent pressure (mm Hg) } & 0.0 \pm 0.7 \\ \text { PA vent pressure (mm } \mathrm{Hg}) & 1.3 \pm 1.8 \\ \text { Aortic injection pressure (mm Hg) } & 39.7 \pm 5.1 \\ \text { CS injection pressure (mm Hg) } & 32.5 \pm 3.1 \\ \text { EAC balloon pressure (mm Hg) } & 475 \pm 33.5 \\ \text { Sinus rhythm after MVR } & 100 \%\end{array}$

Hemodynamic data are expressed as the mean \pm standard deviation. $M T R$, Mitral valve replacement; $C P B$, cardiopulmonary bypass; $P A$, pulmonary artery; $C S$, coronary sinus; $E A C$, endovascular aortic clamp.

respect to within-subject effects in the maximal elastance at both 30 and 60 minutes after the completion of CPB (30 minutes $=4.04 \pm 0.97$ and 60 minutes $=4.27 \pm 0.57$ vs pre $-\mathrm{CPB}=4.45 \pm 0.96$; $p=0.51$ ) (Fig. 4). There were also no significant changes in the PRSW ( 30 minutes $=76.23 \pm 4.80$ and 60 minutes $=71.21 \pm 2.99$ vs pre-CPB $=$ $71.23 \pm 3.75 ; p=0.45$ ) (Fig. 5). PRWAs were 96\% and $85 \%$ of baseline at 30 and 60 minutes after $\mathrm{CPB}$, respectively $(p=0.40$ ) (Fig. 6). The mean percentage standard deviations were $8 \%$ and $7 \%$ for the variables PRSW and PRWA, respectively. Power analysis of our experimental protocol revealed that with a power of $80 \%$ and a two-tailed $t$ test at the level of $5 \%$, we were able to detect a difference in myocardial function before and after CPB if the percentage difference was greater than $12 \%$ for PRSW and greater than $10.5 \%$ for PRWA. ${ }^{10}$

Echocardiography. Transesophageal echocardiography performed after the procedure demonstrated normal valve leaflet function in all cases. No areas of abnormal flow acceleration were seen, and all valves exhibited normal prosthetic regurgitation (Fig. 7, $A$ and $B$ ). All valves appeared to be seated properly. In addition, ventricular wall motion and 


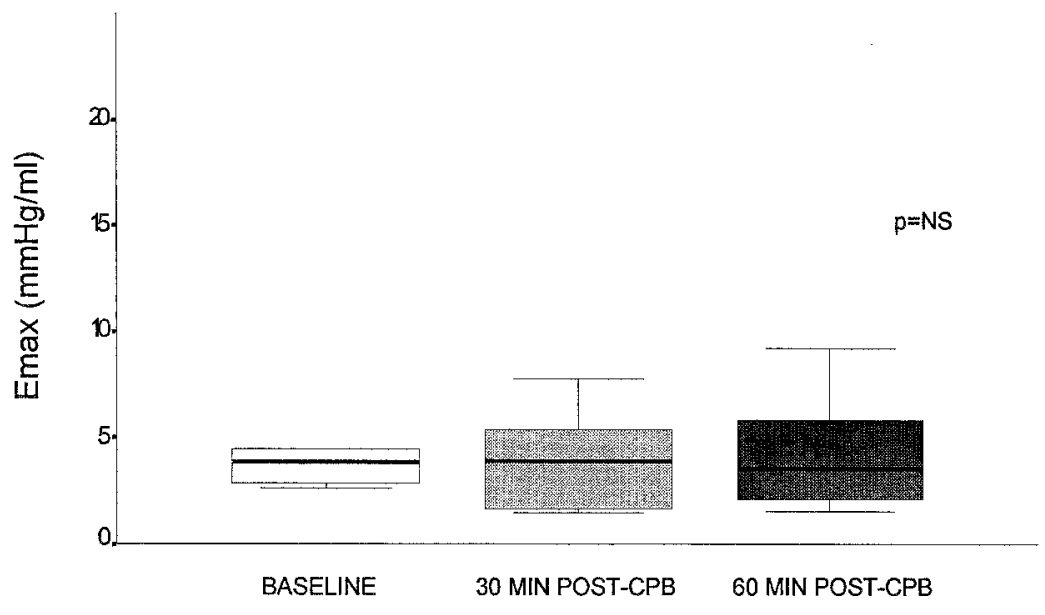

Fig. 4. Maximal elastance (Emax) of the end-systolic pressure-volume relationship represented as boxplots of the mean values before and after CPB. NS, Not significant. $p=0.51$.

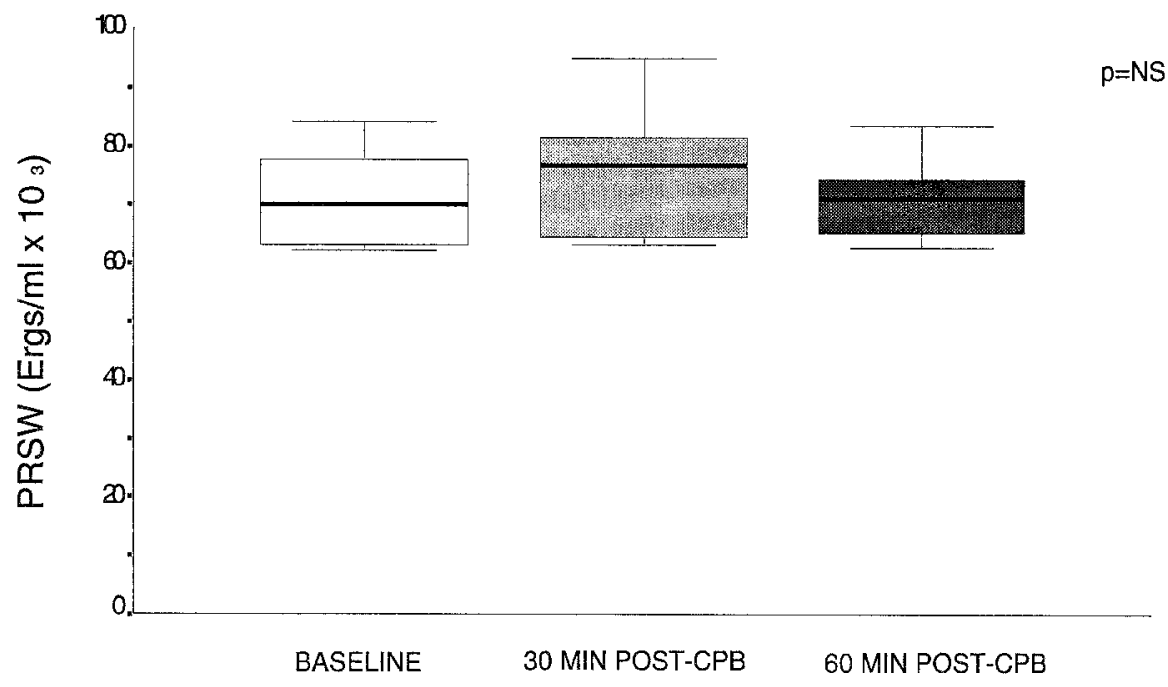

Fig. 5. PRSW of the end-diastolic pressure-volume relationship represented as boxplots of the mean values before and after CPB. NS, Not significant. $p=0.45$.

septal motion appeared normal in each region of the heart in all cases.

Autopsy. After completion of the procedure and acquisition of all data, the animals were put to death and an autopsy was performed. Sutures appeared to be appropriately placed in the anulus and securely tied, demonstrating secure annular-sewing apposition with normal valve leaflet motion. The myocardium had no areas of gross hemorrhage or infarct. The aortic root of all animals appeared normal. The coronary sinus had no areas of gross hemorrhage or damage, and in the two cases that were not amenable to cannulation, the ostia were noted to be small.

\section{Discussion}

Previous studies by Stevens and coworkers ${ }^{11,12}$ and from our laboratory ${ }^{1}$ have demonstrated an effective method of performing closed chest CPB and cardioplegic arrest with endovascular aortic occlusion. On the basis of that capability, this study was designed to apply this technology and evaluate a method of port-access minimally invasive mitral valve replacement. As originally proposed by Pompili and colleagues, ${ }^{13}$ this study describes a closed chest method of mitral valve replacement in a canine model, without the need for median sternotomy or a large thoracotomy. The results from both 


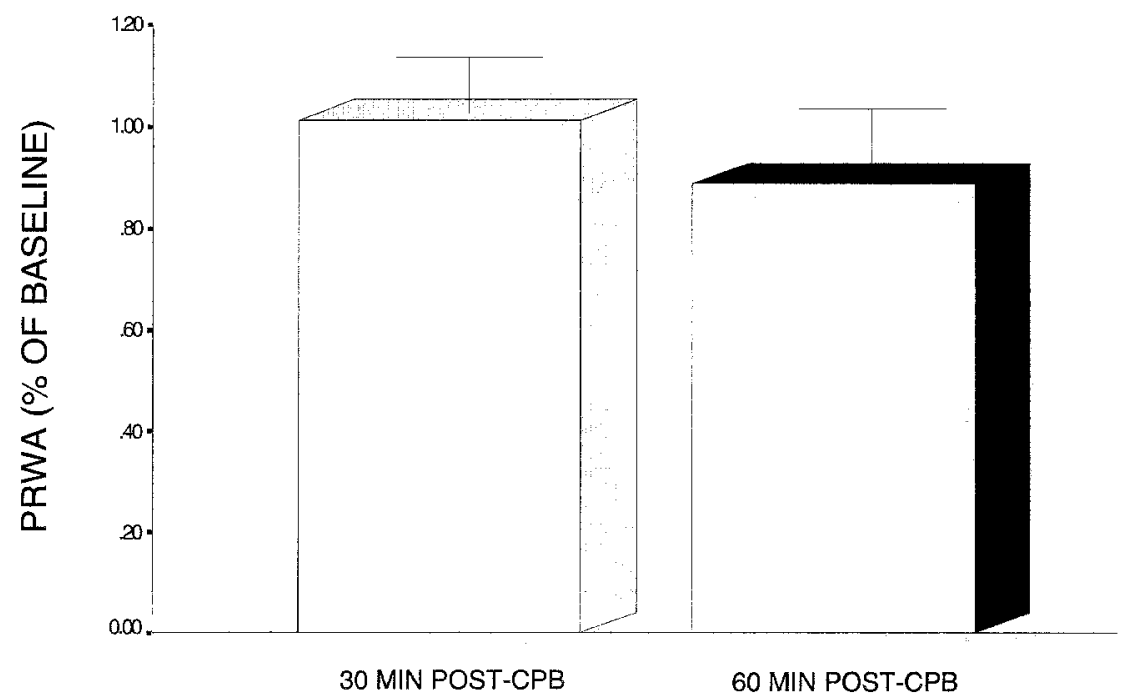

Fig. 6. Myocardial contractile function quantified by PRWA as a percentage of the mean pre-CPB value. $p=0.40$.

the Stanford and the New York University laboratories suggest that this technique is highly reproducible.

Certainly, when one is proposing that a major cardiac procedure such as mitral valve replacement be performed in a minimally invasive manner, the chief concerns are as follows: (1) Is the procedure safe, reproducible, and comparable with the current standard "open" procedure? (2) Are exposure and visualization adequate? (3) Do the instrumentation and technology allow proper valve suture placement, valve seating, and suture tying? (4) Is the final functional result, both in terms of valvular function and myocardial functional recovery, adequate?

On the basis of the present results in this experimental canine model, the answer to all of these questions is yes. The mitral valve was successfully replaced in six mongrel dogs. Exposure was adequate in every case, and the instrumentation allowed adequate valve placement and seating. An important point in assessing the efficacy of any new cardiac surgical technique is to determine the technique's potential for minimizing or worsening myocardial damage during aortic crossclamping. In this study, all measurements of global myocardial performance, including the PRSW, PRWA, and the maximal elastance, were equivalent before and after valve replacement. Likewise, the valve functioned properly in every case. Thus results of the minimally invasive port-access technique of mitral valve replacement appear to be equivalent in every way to the results obtained after standard mitral valve replacement.

A secondary goal of this study was to determine whether percutaneous endovascular delivery of cardioplegic solution could be done in a retrograde fashion, through the coronary sinus, as well as with the previously described antegrade technique. ${ }^{1}$ Successful placement of the percutaneous retrograde coronary sinus catheter was possible in four dogs. Difficulty in cannulating the coronary sinus in one dog may have been due to the relatively small size of the opening of the sinus, as noted at autopsy. In the final case, proper positioning of the coronary sinus catheter was verified, but the cardioplegic solution injection pressure was above $50 \mathrm{~mm} \mathrm{Hg}$ and further retrograde injection was aborted. In both of the cases in which retrograde administration of cardioplegic solution was not successful, the technique was converted to antegrade delivery and myocardial protection was equally effective.

Likewise, decompression of the heart by the endovascular aortic catheter and the endovascular pulmonary artery vent was highly successful, allowing a bloodless operating field. This is thought to be extremely important, because a dry field is essential with a limited exposure technique.

The primary limitation of this study is that a relatively healthy canine model differs in many respects from a human patient with heart disease. Nevertheless, this study attempted to simulate the technique required for removing a diseased valve by 

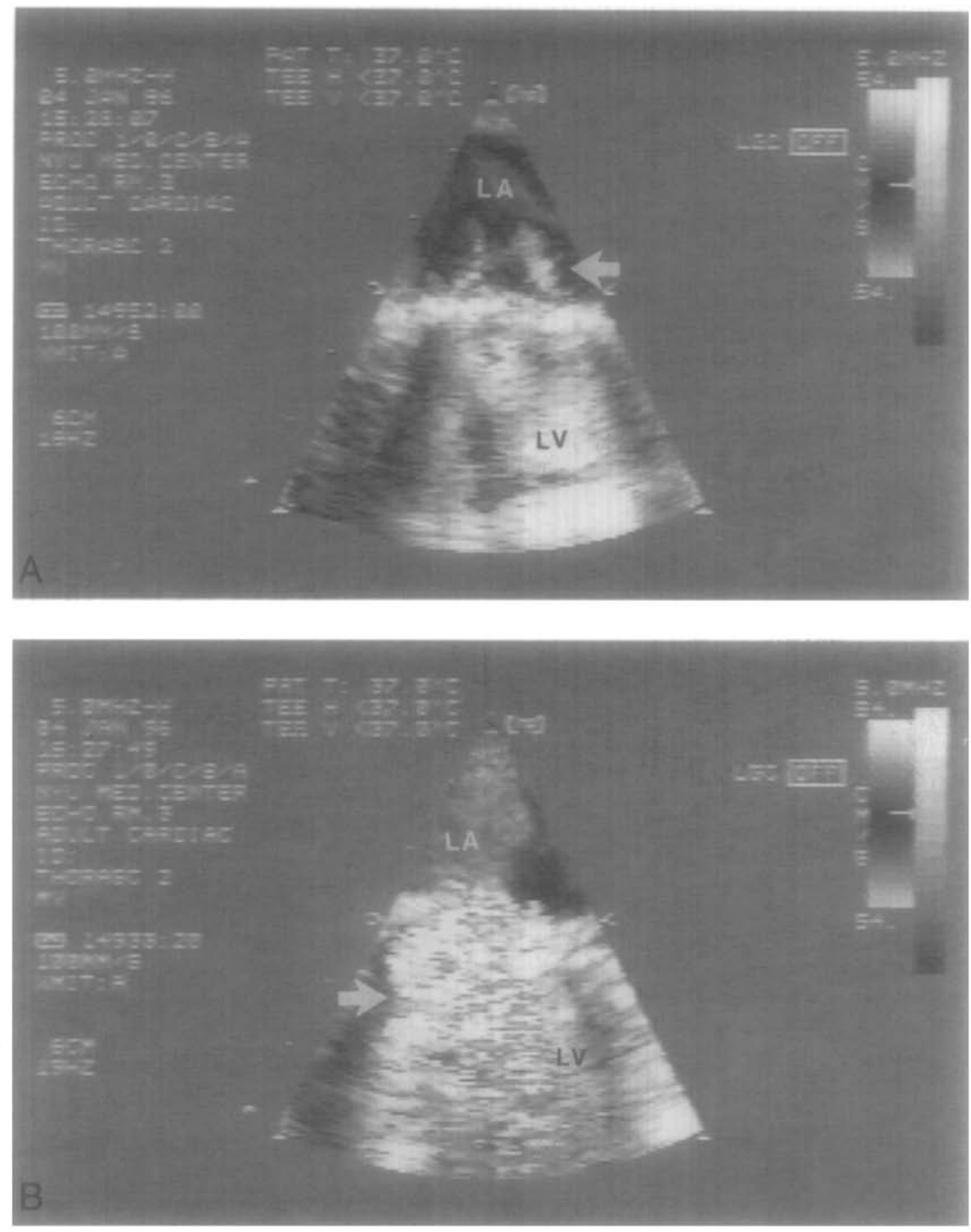

Fig. 7. A, Representative diastolic frame from a transesophageal echocardiogram demonstrating normal mitral prosthetic valvular flow (arrow). B, Representative systolic frame from a transesophageal echocardiogram demonstrating minimal mitral regurgitation (arrow), which is physiologic for a St. Jude Medical prosthesis. No perivalvular leak or areas of abnormal flow acceleration are present. $L A$, Left atrium; $L V$, left ventricle).

excising the anterior mitral leaflet in every case while preserving the posterior leaflet. Although the shape of the canine chest differs from that of humans in that the human chest cavity is much broader and wider, ${ }^{11}$ this study nevertheless demonstrates the overall feasibility of a minimally invasive port-access technique using newly designed technology (Heartport). In human beings a left lateral or third or fourth intercostal space incision may give similar excellent access to the left atrium. Also, on the basis of preliminary clinical trials, a limited right anterior thoracotomy may provide excellent access. Use of innovative endovascular access devices in combination with peripheral CPB has provided the technologic advance necessary to make minimally invasive port-access mitral valve replacement a reality. The findings of this study demonstrate that port-access mitral valve replacement is technically feasible, reproducible, and effective. The overall results demonstrate that the endovascular CPB system (Heartport) was able to provide complete aortic occlusion, adequate cardioplegic delivery and myocardial protection, effective myocardial venting, and excellent return of myocardial function. The implications of these findings are significant, because the methods used in this study may set the groundwork 
for the development of less invasive mitral valve procedures in patients. Clinical trials with minimally invasive mitral valve repair or replacement using the port-access technique are now in progress.

\section{REFERENCES}

1. Schwartz DS, Ribakove GH, Grossi EA, et al. Minimally invasive cardiopulmonary bypass with cardioplegic arrest: a closed chest technique with equivalent myocardial protection. J Thorac Cardiovasc Surg 1996;111:556-66.

2. Baan J, Van Der Velde ET, Van Dijk AD, Kerkof PLM, Buis B, Koops J. Ventricular volume measured from intracardiac dimensions with impedance catheter: theoretical and experimental aspects. In: Kenner T, Busse R, Hinghofer-Szalkay $\mathrm{H}$, et al, editors. Cardiovascular system dynamics: models and measurements. New York: Plenum Press; 1982. p. 569-79.

3. Burkoff D, Van Der Velde ET, De Bruin HG, et al. Continuous measurement of left ventricular volume in animals and humans by conductance catheter. Circulation 1984; 70:812-23

4. Kass DA, Yamazaki T, Burkoff D, Maughan WL, Sagawa K. Determination of left ventricular end-systolic pressure-volume relationships by the conductance (volume) catheter technique. Circulation 1986;78:736-45.

5. Baan J, Van Der Velde ET, Steendijk P, Koops J. Calibration and application of the conductance catheter for ventricular volume measurement. Automedica 1989;111:357-65.

6. Sagawa K, Maughan L, Suga H, Sunagawa K. Chamber pressure-volume relation versus muscle tension-length relation. In: Sagawa K, Maughan L, Suga H, Sunagawa K, editors. Cardiac contraction and the pressure-volume relationship. 1st ed. New York: Oxford University Press; 1988. p. 42-109.

7. Glower DD, Spratt JA, Tyson GS, et al. Linearity of the Frank-Starling relationship in the intact heart: the concept of preload recruitable work. Circulation 1985;71:994-1009.

8. Suga H, Sagawa K, Shoukas AA. Load independence of the instantaneous pressure-volume ratio of the canine left ventricle and the effects of epinephrine and heart rate on the ratio. Circ Res 1973;32:314-22.

9. Suga $H$, Sagawa $K$. The ventricular pressure-volume diagram revisited. Circ Res 1974;43:667-87.

10. Snedecor GW, Cochran WG. Power of a test of significance. In: Snedecor GW, Cochran WG, editors. Statistical methods. 7th ed. Iowa: The Iowa State University Press; 1980. p. 68-70.

11. Stevens JH, Burdon TA, Peters WS. Port-access coronary artery bypass grafting: a proposed surgical method. J Thorac Cardiovasc Surg 1996;111:567-573.

12. Stevens JH, Siegel LC, Mitchell RS, et al. Closed-chest coronary artery bypass with cardioplegic arrest in the dog [abstract]. Circulation 1994;90:251.

13. Pompili MF, Stevens JH, Burdon TA, et al. Port-access mitral valve replacement in dogs. J Thorac Cardiovasc Surg 1996;112:1268-74.

\section{Discussion}

Dr. W. R. Eric Jamieson (Vancouver, British Columbia, Canada) [read by the moderator in Dr. Jamieson's absence]. Dr. Schwartz and associates have demonstrated that minimally invasive mitral valve replacement is technically feasible with port-access technology. They have shown that the procedure can be performed with acceptable ischemic and CPB times. Maximal elastance and PRSW have demonstrated preservation of myocardial function. The procedure is complicated by six vascular access maneuvers to accomplish CPB, monitoring, endovascular aortic occlusion, cardioplegic delivery, and chamber venting. Three of these access maneuvers require fluoroscopy and radiopaque dye for placement of the endovascular aortic clamp.

I have not performed the procedure with port-access technology. I have considerable experience with mitral valve replacement in a sheep model for anticalcification studies of new technology. These procedures were performed through a limited anterior thoracotomy in the left fourth intercostal space.

I have several comments and a few questions for the authors. The ability to control factors that are of potential risk to the animal and subsequent future patients is of most concern. There is a definite need for external defibrillation, as was used in the experimental endeavor. These procedures are satisfactory but must be totally acceptable for clinical use. I have recently observed Dr. Alain Carpentier's video presentation of mitral valve repair using minimally invasive techniques. The procedure was difficult and defibrillation was a problem. The patient's course in the hospital was not shortened by the procedure.

It has been stated that the concept of minimally invasive surgery is patient driven. I am concerned that adequately informing the patients of the lack of ability to control special compromising circumstances may reduce patient enthusiasm. There are several potential devastating complications with the procedure, such as (1) atheromatous embolization with femoral cannulation and retrograde flow and (2) displacement of the endovascular aortic clamp with compromise of cerebral and coronary perfusion.

My questions are few. What is the total potential length of the procedure with extensive vascular access?

Dr. Schwartz. The study presented here is an animal experiment. However, I can outline briefly the length of the procedure both for this animal study and for clinical studies in human beings. The approach and catheter placement are different and, most important, the scope of the procedures performed is more extensive with respect to our clinical trial. In these animal studies, it took about half an hour to place all of these catheters with the exception of the retrograde coronary sinus catheter. Whereas this was particularly difficult to place in this canine model, in human studies placement was not at all difficult, and all attempts to date have been successful. As presented in this animal study, it took an average of 88 minutes to perform this procedure with $\mathrm{CPB}$, after which weaning from CPB and collection of the data lasted about another 60 to 70 minutes.

In our clinical experience, we, along with Stanford University, are part of a phase I clinical trial using this port-access system for mitral valve repair and replacement. At New York University Medical Center we have successfully repaired and/or replaced the mitral valve in seven patients. The phase I trial has been completed and has been resubmitted to the Food and Drug Administra- 
tion. The complexity of the procedure really determines how much time it takes to complete it. During this phase I trial, we performed not only mitral valve replacement but mitral valve repairs. Therefore, how long it would take in the clinical setting is quite variable.

Dr. Jamieson. Do you operate with lead protection for the need of repeat fluoroscopy?

Dr. Schwartz. In these first few cases, we operated with lead protection throughout the procedure. After the sixth case everybody was quite tired from the lead, but in the beginning, with our increased enthusiasm, we did not feel the need to remove the lead. It did not bother us very much.

Dr. Jamieson. Do you think there will be a medicolegal issue with concern over the risk of the procedure, induced complications, and lack of ready access for control of infrequent but uncontrollable complications from portaccess techniques?

Dr. Schwartz. I cannot really answer that question at this time, but I think a sufficient safety net is in place. As was mentioned in the discussion, there was some concern over placement of the balloon, slippage of the balloon, deflation of the balloon, and occlusion of the head vessels. Many safety mechanisms are built into the procedure. For example, we monitor both arterial and aortic root pressures to look for a difference in pressure to help determine whether the balloon has slipped. We also monitor the balloon pressure throughout the entire procedure. If there is a concern, we use fluoroscopy to reevaluate the position of the catheter. The visual access to the mitral valve in these clinical cases was excellent, so I am not sure that there would be much of a concern over that aspect.

Dr. Jamieson. I congratulate you on an elegant experimental study demonstrating feasibility in minimally invasive mitral valve surgery. Several questions remain: Where do we go from here? Which patients do we select? How do we train cardiac surgeons? What is the cost/benefit ratio of the technique? Do we need a controlled randomized trial before embarking on general availability of portaccess equipment to the marketplace?
Dr. D. Craig Miller (Stanford, Calif.). Dr. Schwartz, who did the calculations of left ventricular systolic mechanics?

Dr. Schwartz. I did the calculations.

Dr. Miller. You said that you used a conductance catheter to measure left ventricular volume, yet your depiction of systolic elastance PRSW or PRWA are all measured per centimeter and not per milliliter. I assume your conductance catheter did not work or you did not believe it, which is more often the case, and you relied instead on echo dimension. Can you amplify?

Dr. Schwartz. Maximal elastance was measured in milliliters. This was a typographical error on the illustration. The illustration showing PRSW is discussing volume. This is depicted in centimeters cubed for the preload, so I believe that is correct.

Dr. Julian Smith (Melbourne, Australia). We have conducted similar studies in our laboratory with a couple of variations. We have been able to successfully do the procedure through a right thoracotomy in the dog model, just further mimicking the human situation. We have also done a series of deairing studies looking for residual cardiac air and the incidence of embolization of air to the periphery, and we have found a very low incidence and very satisfactory results with the deairing techniques we have used.

Dr. William Brenner (Hackensack, N.J.). I saw the video at meeting of the New York Thoracic Society and it was very impressive. How much contrast material would you estimate is used in the human clinical situation? Are you concerned, in the high-risk elderly patient, about the synchronous effect of contrast material plus CPB insult to the kidneys?

Dr. Schwartz. The amount of contrast material is negligible compared with that used in other vascular angiographic techniques. In fact, a lot of the contrast material is actually given into the balloon catheters. I would estimate that less than 20 to $25 \mathrm{ml}$ of a $50 \%$ solution of radiopaque contrast is given in total. 